\title{
Assessing frailty in the acute medical admission of elderly patients
}

\author{
${ }^{1} \mathrm{MT}$ Oo, ${ }^{2} \mathrm{~A}$ Tencheva, ${ }^{3} \mathrm{~N}$ Khalid, ${ }^{4} \mathrm{YP}$ Chan, ${ }^{5} \mathrm{SF}$ Ho \\ ${ }^{1}$ Specialist Registrar; ${ }^{2} \mathrm{FY} 1$ House Officer; ${ }^{3} \mathrm{CT} 1 ;{ }^{4}$ Consultant, Department of Geriatric Medicine, Good Hope Hospital, Heart of England NHS \\ Foundation Trust, Birmingham, UK; ${ }^{5}$ Consultant, Department of Geriatric Medicine, Royal Shrewsbury Hospital, Shrewsbury, UK
}

\section{ABSTRACT}

Background: Managing acute admission of frail older patients is a challenge in hospitals. Length of inpatient stay, inpatient mortality and the 90 -day readmission rate are significant in this group of patients. The Comprehensive Geriatric Assessment (CGA), a multidisciplinary diagnostic and treatment process, is the best approach for identifying medical conditions, mental health, functional capacity and social circumstances in acute geriatric care.

Methods: A review of the records of older patients aged 75 and over, acutely admitted to a district general hospital in England from 15 March 2012 to 16 April 2012 was conducted. We developed a frailty assessment tool and applied it to these patients, in order to determine who would be classified as frail. We then established if the patients meeting this criteria were then correctly assessed using the CGA.All patient data were processed and analysed using a statistical package for data analysis.

Results: A total of 232 patients with a mean age of $84.25 \pm 5.8$ years were included. Out of these, 129 patients $(55.6 \%$ ) fulfilled the frailty criteria as determined with our frailty-assessment tool; $80.6 \%$ presented with lack of mobility over 24 hours, $69.8 \%$ were admitted with falls, $47.3 \%$ had known dementia or delirium and $45 \%$ were admitted from care homes. Patients aged over 85 years were more likely to have frailty compared with patients aged 75-85 years old (odds ratio [OR]: $4.78,95 \%$ confidence interval $[\mathrm{Cl}]: 2.6-8.6, \mathrm{p}$ value $<0.00 \mathrm{I}$ ). Patients assessed by a front door geriatric team were more likely to be reviewed with the CGA than those not seen by this team (adjusted OR $2.8,95 \% \mathrm{Cl}: \mathrm{I}-7.6, \mathrm{p}$ value $=0.04$ ).

Conclusion: The prevalence of frailty is high in acute admissions of older patients and it is important that they are properly identified and assessed with a CGA in order to ensure effective multidisciplinary care.

KEYWORDS Acute elderly care, frailty screening, comprehensive geriatric assessment

DECLARATION OF INTERESTS No conflicts of interest declared.

\author{
Correspondence to $M T$ Oo \\ Department of Geriatric Medicine \\ Good Hope Hospital \\ Heart of England \\ NHS Foundation Trust \\ Birmingham, B75 7RR UK
}

tel. +44 (0) I 2 I 4242000

e-mail moethaw.oo@nhs.net

\section{INTRODUCTION}

The number of patients aged 75 and over being admitted to acute medical beds has grown at a greater rate than any other age group over the past decade. Admissions of this particular age group increased significantly, by two-thirds between 2000 and 2010;' total hospital admissions of these patients was 2,308,480 in 1999/2000, increasing to $3,837,990$ in $2009 / 2010 .^{2}$ Frail older people represented a larger proportion of acute admissions. Half of these patients, who were rapidly discharged from acute medical care, were re-admitted within the first 90 days following discharge. Moreover, one-third of these frail elderly patients died within a year of discharge. ${ }^{3}$ The length of inpatient stay and mortality rate were also higher than among non-frail older patients. ${ }^{4}$ TheWoodard et al. study of frail, older inpatients concluded that this group of patients had a higher risk of a long hospital stay and the speedy discharge of these patients did not always serve them well. ${ }^{5}$ In these circumstances, systematic screening for frailty and appropriate integrated management are required for frail elderly inpatients.

The Comprehensive Geriatric Assessment (CGA) process is the best approach in providing this integrated management of acute care for elderly patients. ${ }^{3}$ It is a multidimensional diagnostic process, made up of five core assessment components to determine a frail, older person's medical, psychological, social, environmental and functional capabilities in order to develop a coordinated and integrated plan for treatment and follow-up. Undertaking a CGA could increase patients' survival and 
possibility of stay in their own residences by up to 12 months. Patients who were provided with integrated geriatric medical care gained better overall outcomes than those who were given general medical care. ${ }^{6}$

\section{DEFINING FRAILTY}

Frailty is a complex geriatric process but is not a new concept. It should be considered when an older person, under any stressful circumstance, has reduced capacity to undertake the fundamental activities of daily living. It occurs as a result of the combination of illnesses and the physiological changes associated with ageing. ${ }^{7}$ As a complex geriatric syndrome, frailty is a characteristic of multi-system impairments in the body. ${ }^{8}$ It is an important factor in causing falls and falls can be the presenting clinical feature of the frail older person. ${ }^{8}$ Frailty can increase the severity of incidental fractures and mortality. ${ }^{9}$ A systematic review relating to frailty and fractures concluded that the absolute risk of incidental fractures and mortality are significantly higher in frail people.' An American observational cohort study of community-dwelling older people proposed that frailty increases the risk of mild cognitive impairment $(\mathrm{MCl})$ as well as its severity. ${ }^{10}$ It is also associated with a high incidence and prevalence of Alzheimer's dementia." $A$ UK national survey of care home residents has shown that about $70 \%$ of care home places are occupied by frail older residents with multiple co-morbidities, such as dementia and stroke. ${ }^{12}$ There is a relationship between frailty, reduced mobility, lack of physical activity and advanced age. ${ }^{13}$ All these parameters are connected and influence the definition of frailty. ${ }^{13}$

\section{Designing a frailty screening tool}

Frailty is a complex and dynamic condition, making screening for it a challenging task. It is clinically significant however and should be assessed appropriately and effectively. There are different frailty assessment tools, each designed and implemented among various target elderly populations in different communities. In 200I Fried provided one of the first systematic and scientific approaches for the assessment of frailty, where they highlighted five key criteria: ${ }^{14}$

- Slow mobility

- Low physical activity

- Self-reported exhaustion

- Muscle weakness or poor grip strength

- Unintentional weight loss

The International Academy on Nutrition and Ageing (IANA) frailty assessment scale is also based on five subjective questions: ${ }^{15}$

- Fatigue: Does he or she easily feel fatigue or tired?

- Resistance: Can he or she climb one flight of stairs?
- Aerobic: Can he or she walk one block?

- IIIness: Does he or she currently suffer any acute illness?

- Loss of weight: Does he or she have recent weight loss?

University Hospitals of Leicester has set up an Acute Frailty Unit aimed at reducing the number of readmissions of older people and improving health outcomes by undertaking assessment within the Emergency Department. Their criteria include: ${ }^{4}$

- Age (70 and over)

- Fracture (not fracture of neck of femur) with any unstable medical condition

- Care home residence

- State of acute or chronic confusion

- AWaterlow score of over 25.

Although many assessment tools and screening scales have emerged over the past decade, no single scale is universally accepted, possibly due to their limitations. A systematic literature review on the identification of frailty proposes that designing a screening tool should directly reflect and relate to the purposes for identifying frailty in target older populations. ${ }^{16}$ For example, a tool designed for a research study or a randomised controlled trial might be different from that designed for daily clinical use, again, another reason for the lack of generally accepted single tool. It should be created in recognition of local need and proposed applications. For example, a frailty tool should be designed as a simple and user-friendly scale if it is to be implemented in daily clinical practice. ${ }^{16}$

\section{OUR FRAILTY ASSESSMENT TOOL}

For the purposes of our review, we developed a frailty assessment tool with the following aims: it must be simple and clear, useful for clinical practice, applicable for use as a quick assessment in busy clinical settings, and easily used by any member of the acute admission team. We established the following criteria:

- Age (75 and over)

- Fall with any injury or fracture (excluding fracture of neck of femur)

- Evidence of dementia or delirium

- Care home residence

- Reduced or lack of mobility over 24 hours

We applied this criteria to the patients in our study and determined that if any acute elderly inpatient met at least three out of five of these criteria, they should be diagnosed as having frailty and this indicated the need for a CGA. 
Validating our frailty screening tool

\section{Strengths}

A reliable measurement scale has high quality precision and accuracy. ${ }^{17}$ For the purpose of clinical research methodologies, precision is defined as the degree to which the same results are gained in repetitive use and accuracy is described as the degree to which the collected results actually represent what they are supposed to represent. ${ }^{17}$ Our frailty assessment tool fulfilled these requirements:

- Apart from the criterion 'reduced or lack of mobility over 24 hours,' the rest of the parameters of the frailty assessment tool are standardised fixed criteria. ${ }^{17}$ The validity of these parameters should therefore be recognised as 'constant' while applying to any group of patients in any clinical circumstance.

- The rate of inter-observer reproducibility was tested (by two different observers: two different grades of doctor, a doctor and a physiotherapist assessed five patients with the tool). ${ }^{17}$

- The rate of intra-observer reproducibility was tested (by one observer: a doctor assessed the same patient in different settings - in the acute admission unit and the ward. This was also carried out with five patients). ${ }^{17}$

- No observers involved in the validation of the scale contributed to any part of the survey. They were independent observers. The risk of researcher bias is therefore minimised in the validation process of this scale.

\section{Weaknesses}

- The 'reduced or lack of mobility over 24 hours' criteria is a subjective factor in identifying frailty and it might vary from patient to patient.

- A total of ten patients were involved in testing inter- and intra-observer reproducibility (five each).

- A small sample size could increase the chance of standard error ${ }^{18}$ and affect the precision of this measurement tool.

\section{OUR STUDY}

\section{Objectives}

Our review was aimed at assessing the prevalence of frailty in acute older admissions to our hospital and evaluating the number of these patients who were given a CGA.

\section{Methods}

We reviewed the records of older patients aged 75 and above, who were acutely admitted to a district general hospital in England during office hours ( 9 am to $5 \mathrm{pm}$ ), on weekdays from I5 March 2012 to 16 April 2012. Using a specific data collection proforma we applied our frailty screening tool.

All patient data were processed and analysed using a statistical package for data analysis. The characteristics of all study patients were examined with frequency tabulations, showing actual observations, the percentage and $95 \%$ confidence interval $(\mathrm{Cl})$. The prevalence of frailty was determined using our frailty assessment tool. We used the chi-squared test to compare our definition of frailty with the patient characteristics. Using logistic regression we determined the association between an assessment of frailty and the application of the CGA. Odds ratio $(O R)$ estimates and $95 \% \mathrm{Cl}$ were obtained and the Wald test was used as a significance test.

\section{Limitations in data collection and analysis}

As data collection was undertaken only during office hours on weekdays, every older patient aged 75 and over acutely admitted to the hospital outside these hours within the one month study period could not be involved in the study. It made the sample population size smaller, which might have increased the risk of standard error and affected how precisely the sample population represented the whole target population. ${ }^{18}$ Our study focused only on older patients who were admitted acutely for medical causes and therefore it did not include other older patients acutely admitted to the hospital for non-medical causes (such as acute surgical admissions). Underlying co-morbidities such as malignancy and unhealthy lifestyles (i.e. smoking) were not accounted for in our study and these factors may be regarded as confounding, which could affect frailty measurement and overall outcomes of the study. ${ }^{18}$

\section{RESULTS}

\section{Characteristics of all study patients in our study}

The study group was composed of 232 older patients, aged between 75 and 102 years, with a mean age of $84.25 \pm 5.8$ years. More than half of the patients were female $(n=\mid 42,61.2 \%)$. The majority of patients were located in the Acute Medical Unit (AMU), $(n=169$, 72.8\%) (Table I).

\section{Results of the application of the frailty assessment tool}

Out of all the patients admitted, $53 \%$ had falls with an injury or fracture, $28.9 \%$ had dementia or delirium, $28.4 \%$ were care home residents and $55.6 \%$ had a lack of mobility over 24 hours. A total of 129 (55.6\%) patients met at least three out of five of the established criteria and were diagnosed as frail (Table 2). 
TABLE I Characteristics of the patients in our study

\begin{tabular}{|c|c|c|c|}
\hline & \multicolumn{2}{|c|}{ Total $n=232$} & \multirow[b]{2}{*}{$\begin{array}{c}95 \% \\
\text { confidence } \\
\text { interval }\end{array}$} \\
\hline & $\mathbf{n}$ & $\%$ & \\
\hline \multicolumn{4}{|l|}{ Age group (years) } \\
\hline $75-85$ years & 140 & 60.3 & $54-66.7$ \\
\hline Above 85 years & 92 & 39.7 & $33.3-46$ \\
\hline Range (years) & $75-102$ & & \\
\hline Mean age \pm SD & $\begin{array}{c}84.25 \pm \\
5.8\end{array}$ & & \\
\hline \multicolumn{4}{|l|}{ Gender } \\
\hline Male & 90 & 38.8 & $32.5-45$ \\
\hline Female & 142 & 61.2 & $54.9-67.5$ \\
\hline \multicolumn{4}{|l|}{ Patient location } \\
\hline Acute Medical Unit & 169 & 72.8 & $67.1-78.6$ \\
\hline Other location & 63 & 27.2 & $21.4-32.9$ \\
\hline
\end{tabular}

TABLE 2 Results of the application of the frailty assessment tool

\begin{tabular}{|c|c|c|c|}
\hline & \multicolumn{2}{|c|}{ Total $n=232$} & \multirow[b]{2}{*}{$\begin{array}{c}95 \% \\
\text { confidence } \\
\text { interval }\end{array}$} \\
\hline & $\mathbf{n}$ & $\%$ & \\
\hline \multicolumn{4}{|c|}{$\begin{array}{l}\text { Fall with any injury or fracture (excluding fracture of neck } \\
\text { of femur) }\end{array}$} \\
\hline No & 109 & 47 & $40.5-53.5$ \\
\hline Yes & 123 & 53 & $46.5-59.5$ \\
\hline \multicolumn{4}{|c|}{ Known dementia or delirium } \\
\hline No & 165 & 71.1 & $65.2-77$ \\
\hline Yes & 67 & 28.9 & $23-34.3$ \\
\hline \multicolumn{4}{|l|}{ Care home residence } \\
\hline No & 165 & 71.1 & $65.2-77$ \\
\hline Yes & 66 & 28.4 & $22.6-34.3$ \\
\hline \multicolumn{4}{|c|}{ Lack of mobility over 24 hours } \\
\hline No & 103 & 44.4 & $38-50.8$ \\
\hline Yes & 129 & 55.6 & $49.2-62$ \\
\hline \multicolumn{4}{|c|}{ Defined as frail (three out of five criteria) } \\
\hline No & 103 & 44.4 & $38-50.8$ \\
\hline Yes & 129 & 55.6 & $49.2-62$ \\
\hline
\end{tabular}

\section{Characteristics of frail patients}

Among the patients who were diagnosed as being frail, more than half $(55 \%)$ were aged 85 years and over, with a mean age of $86.6 \pm 5.4$ years; $65.1 \%$ were female and $69.8 \%$ were located in the AMU. Among frail patients, $69.8 \%$ had falls with an injury or fracture, $47.3 \%$ had known dementia or delirium, $45 \%$ were care home residents and $80.6 \%$ were affected by a lack of mobility over 24 hours. Almost $40 \%$ of all frail patients are seen by the front door geriatric team and about $43 \%$ received a complete CGA (Table 3).

\section{Comprehensive Integrated Geriatric Assessments received by patients}

The CGA is made up of a number of core components, not all of which are applied to every patient. In our study we found that $60.8 \%$ of frail patients were assessed for cognitive function using the abbreviated mental test score (AMTS) or the mini mental state exam (MMSE); a review of pre-admission social circumstances and mobility were both carried out for all patients. Assessments for other components, such as other acute medical conditions and the patient's nutritional status (using a 24-hour food intake chart) were higher among frail patients who were not seen by a front door geriatric team, at $100 \%$ and $91 \%$, respectively. Around $55 \%$ of frail patients seen by a front door geriatric team were assessed using every component of a CGA, while only around $35 \%$ who were not seen by a front door geriatric team were assessed against all of them (Figure I).

The association between characteristics of all patients admitted to the hospital and having frailty

Univariate analysis shows that age is a strong predicting factor for frailty. Older patients aged over 85 years are more likely to be frail compared to patients aged 75-85 years old (OR: 4.78, 95\% Cl: 2.6-8.6, p value <0.00I). Gender and patient location are not associated with having frailty.

\section{The associations between characteristics of frail patients and receiving a CGA}

Univariate analysis shows that age, gender, known dementia or delirium and visits by a front door geriatric team are predicting factors for receiving a CGA. Older frail patients (aged over 85 years) were more likely to receive a CGA compared to patients aged $75-85$ years (OR: 2. I, 95\% Cl: I-4.3, p value=0.04). Female patients with frailty were more likely to receive a CGA compared with male patients (OR: 3.4, 95\% Cl: 1.5-7.6, $\mathrm{P}$ value 0.003). Those patients with known dementia or delirium were more likely to receive a CGA compared with those who did not have dementia or delirium (OR: 20.I, 95\% Cl: 8. I-50. I, p value $<0.00$ I). Frail patients who are seen by a front door geriatric team are more likely to receive a CGA compared with patients who are not (Table 5).

The association between characteristics of frail patients and receiving a CGA, adjusted for other variables

Multivariate analysis shows that after adjusting for age group, gender, known dementia or delirium and being assessed by a front door geriatric team, known delirium or dementia (adjusted OR 19.8, 95\% Cl: 7.4-53.2, p value $<0.00 \mathrm{I}$ ) and being seen by the team (adjusted OR 2.8, 
TABLE 3 Characteristics of frail patients

\begin{tabular}{|c|c|c|c|}
\hline & \multicolumn{2}{|c|}{ Total $n=232$} & \multirow[b]{2}{*}{$\begin{array}{c}95 \% \\
\text { confidence } \\
\text { interval }\end{array}$} \\
\hline & $\mathbf{n}$ & $\%$ & \\
\hline \multicolumn{4}{|l|}{ Age group (years) } \\
\hline $75-85$ years & 58 & 45 & $36.3-53.7$ \\
\hline Above 85 years & 71 & 55 & $46.3-63.7$ \\
\hline Mean age $\pm S D$ & $86.6 \pm 5.4$ & & \\
\hline \multicolumn{4}{|l|}{ Gender } \\
\hline Male & 45 & 34.9 & $26.5-43.2$ \\
\hline Female & 84 & 65.1 & $56.8-73.5$ \\
\hline \multicolumn{4}{|l|}{ Patient location } \\
\hline Acute Medical Unit & 90 & 69.8 & 6I.7-77.8 \\
\hline Other location & 39 & 30.2 & $22.2-38.3$ \\
\hline \multicolumn{4}{|c|}{ Frailty assessment tools } \\
\hline \multicolumn{4}{|c|}{$\begin{array}{l}\text { Fracture with any injury or fracture (excluding fracture of } \\
\text { neck of femur) }\end{array}$} \\
\hline No & 39 & 30.2 & $22.2-38.3$ \\
\hline Yes & 90 & 69.8 & $61.7-77.8$ \\
\hline \multicolumn{4}{|c|}{ Known dementia or delirium } \\
\hline No & 68 & 52.7 & $44-61.4$ \\
\hline Yes & 61 & 47.3 & $38.6-56$ \\
\hline \multicolumn{4}{|l|}{ Care home residence } \\
\hline No & 70 & 54.3 & $45.6-63$ \\
\hline Yes & 58 & 45 & $36.3-53.7$ \\
\hline \multicolumn{4}{|c|}{ Lack of mobility over 24 hours } \\
\hline No & 25 & 19.4 & $12.5-26.3$ \\
\hline Yes & 104 & 80.6 & 73.7-87.5 \\
\hline \multicolumn{4}{|c|}{ Seen by front door geriatric team } \\
\hline No & 78 & 60.5 & $51.9-69$ \\
\hline Yes & 51 & 39.5 & $31-48$ \\
\hline
\end{tabular}

95\% Cl: I-7.6, $\mathrm{P}$ value=0.04) are still significantly associated with receiving a CGA and constitute major predicting factors (Table 6).

\section{DISCUSSION}

According to our results, 129 out of a total of 232 patients $(55.6 \%)$ fulfilled the frailty screening criteria. This clearly shows that frailty is common among older acute medical admissions and it is also directly proportionate to advanced age; frailty was found in 71 patients $(55 \%$ of the total 129 frail patients) aged 85 and above.

Lack of mobility over 24 hours was the most common frailty feature in older patients in our study (80.6\%); the second most common characteristic feature was falling (69.8\%). These findings highlight that mobility assessment,

fall risk reduction, prevention and management are vital in hospitalised older frail people. These services are involved in the rapid CGA.

A total of $6 \mathrm{I}$ patients (47.3\%) suffered delirium or dementia, demonstrating that either acute or chronic cognitive impairment is related to frailty in old age. It highlights the importance of cognitive function assessment in this particular group of patients. According to our findings, 67 frail patients (51.9\%) were given a cognitive function assessment with appropriate mental test scoring such as abbreviated mental test score (AMTS), while 62 patients (48.I\%) were not. The front door geriatric team provided a cognitive function assessment for $60 \%$ of the frail patients, while other medical teams carried out assessments on approximately $46 \%$ of the total frail patients. These findings clearly show that all frail older patients did not receive a 


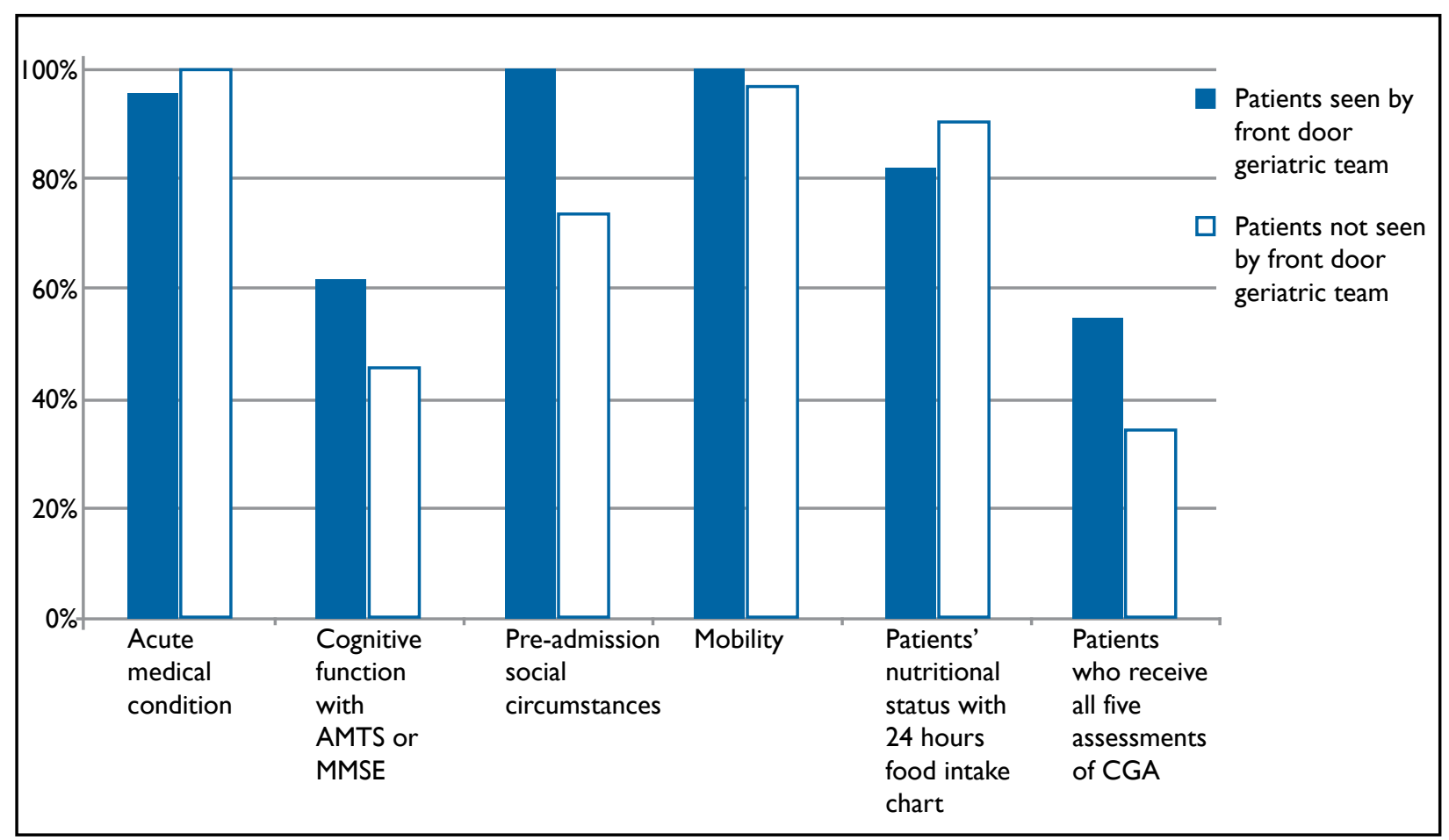

FIGURE I Comprehensive geriatric assessment components assessed in frail patients.

cognitive function assessment. Processes should be established to ensure that every frail elderly patient acutely admitted to hospital receives a cognitive function assessment.

A total of 58 patients (45\%) were admitted from care homes. This suggests that the prevalence of frailty is directly proportionate to institutionalised dwelling. Frailty screening must therefore be conducted in every older patient admitted from care homes regardless of the reasons for hospital admission.

In our study, a total of 55 patients (42.6\%) received a CGA. In terms of the individual components of a CGA (assessing acute medical conditions, mobility status, pre- admission social circumstances and nutritional status), these were conducted satisfactorily (Table 3); over $80 \%$ of the frail patients received these assessments. However 74 patients $(57.4 \%)$ were not assessed against all five core components of the CGA.

The front door geriatric team undertook a CGA for $55 \%$ of all frail patients $(n=5 I)$ that they saw; other medical teams provided it for $34.6 \%$ of their frail patients $(n=78)$. This finding is statistically significant in univariate analysis with evidence of more patients seen by a front door geriatric team receiving CGA than those seen by non-geriatric medical teams (OR: 2.3, 95\% Cl:I.I-4.7, P value $=0.02$ [Table 5]). Results of the multivariate analysis also suggest that patients assessed by a front door

TABLE 4 The association between patients' characteristics and having frailty (univariate analysis)

\begin{tabular}{|c|c|c|c|c|c|}
\hline \multicolumn{6}{|c|}{ Total $n=232$} \\
\hline & Total n & $\%$ of frailty & Odds ratio & $\begin{array}{l}95 \% \text { confidence } \\
\text { interval }\end{array}$ & p value \\
\hline Age group & & & & & $<0.001$ \\
\hline $75-85$ years & 140 & 41.4 & I & & \\
\hline Above 85 years & 92 & 77.2 & 4.78 & $2.6-8.6$ & \\
\hline Gender & & & & & 0.2 \\
\hline Male & 90 & 50 & I & & \\
\hline Female & 142 & 59.2 & 1.86 & $0.9-2.5$ & \\
\hline Patient location & & & & & 0.2 \\
\hline Other location & 63 & 61.0 & I & & \\
\hline $\begin{array}{l}\text { Acute Medical } \\
\text { Unit }\end{array}$ & 169 & 53.3 & 0.7 & $0.4-1.3$ & \\
\hline
\end{tabular}


TABLE 5 The association between characteristics of frail patients and receiving a CGA (univariate analysis)

\begin{tabular}{|c|c|c|c|c|c|}
\hline \multicolumn{6}{|c|}{ Total $n=129$} \\
\hline & Total $\mathbf{n}$ & $\begin{array}{c}\text { \% receiving } \\
\text { Comprehensive } \\
\text { Geriatric } \\
\text { Assessment }\end{array}$ & Odds ratio & $\begin{array}{l}95 \% \text { confidence } \\
\text { interval }\end{array}$ & p value \\
\hline Age group & & & & & 0.04 \\
\hline 75-85 years & 58 & 32.8 & 1 & & \\
\hline Above 85 years & 71 & 50.7 & 2.1 & $1-4.3$ & \\
\hline Gender & & & & & 0.003 \\
\hline Male & 45 & 24.4 & 1 & & \\
\hline Female & 84 & 52.4 & 3.4 & I.5-7.6 & \\
\hline \multicolumn{6}{|l|}{ Patient location } \\
\hline Other location & 39 & 35.9 & 1 & & 0.3 \\
\hline Acute Medical Unit & 90 & 45.6 & 1.5 & $0.7-3.2$ & \\
\hline \multicolumn{2}{|c|}{ Fall with injury or fracture } & & & & 0.07 \\
\hline No & 39 & 30.8 & I & & \\
\hline Yes & 90 & 47.8 & 2.1 & $0.9-4.6$ & \\
\hline \multicolumn{2}{|c|}{ Known dementia or delirium } & & & & $<0.001$ \\
\hline No & 68 & 13.2 & 1 & & \\
\hline Yes & 61 & 75.4 & 20.1 & $8.1-50.1$ & \\
\hline \multicolumn{2}{|l|}{ Care home residency } & & & & I \\
\hline No & 70 & 42.9 & 1 & & \\
\hline Yes & 58 & 43.1 & 1 & $0.5-2$ & \\
\hline \multicolumn{2}{|c|}{ Lack of mobility over 24 hours } & & & & 0.1 \\
\hline No & 25 & 56 & 1 & & \\
\hline Yes & 104 & 39.4 & 0.5 & $0.2-1.2$ & \\
\hline \multicolumn{2}{|c|}{ Seen by front door geriatric team } & & & & 0.02 \\
\hline No & 78 & 34.6 & 1 & & \\
\hline Yes & 51 & 51 & 2.3 & $1.1-4.7$ & \\
\hline
\end{tabular}

TABLE 6 The association between characteristics of frail patients and receiving a CGA (multivariate analysis)

\begin{tabular}{|c|c|c|c|c|}
\hline & Crude odds ratio & Adjusted odds ratio & $\begin{array}{c}95 \% \text { confidence } \\
\text { interval }\end{array}$ & p value \\
\hline Age group & & & & 0.5 \\
\hline 75-85 years & 1 & I & & \\
\hline $\begin{array}{l}\text { Above } \\
85 \text { years }\end{array}$ & 2.1 & 1.3 & $0.5-3.4$ & \\
\hline Gender & & & & 0.2 \\
\hline Male & I & 1 & & \\
\hline Female & 3.4 & 2 & $0.7-5.6$ & \\
\hline \multicolumn{4}{|c|}{ Known delirium or dementia } & $<0.001$ \\
\hline No & 1 & 1 & & \\
\hline Yes & 20.1 & 19.8 & $7.4-53.2$ & \\
\hline \multicolumn{4}{|c|}{ Seen by front door geriatric team } & 0.04 \\
\hline No & 1 & 1 & & \\
\hline Yes & 2.3 & 2.8 & & \\
\hline
\end{tabular}


geriatric team were more likely to receive a CGA than those not seen by them (adjusted OR 2.8, 95\% Cl: I-7.6, $P$ value $=0.04$ [Table 6]). It appears that CGAs are a limited specialised skill within the geriatric medical team. In reality, all clinical teams in a hospital manage frail, elderly acute admissions in daily practice and as a result, performing a CGA must be established as a core common skill across all teams.

Results of both univariate and multivariate analysis show that more frail older patients presenting with delirium and or known dementia were given a CGA than other frail patients who had falls, lacked mobility over 24 hours and were admitted from care homes, though cognitive function assessment alone is not provided to the majority of frail older patients at present. Delirious or frail older patients with dementia appear to be a priority group for receiving a CGA.

\section{REFERENCES}

I The NHS Information Centre for Health and Social Care. Report on NHS hospitals activities 2010 [Internet]. Available from: http:// data.gov.uk/nhs-information-centre-for-health-and-social-care

2 The NHS Information Centre for Health and Social Care. Hospital episode statistics, admitted patient care - England 2009//0. Leeds: HSCIC; 2010.

3 Conroy SP, Stevens T, Parker SG et al. A systematic review of comprehensive geriatric assessment to improve outcomes for frail older people being rapidly discharged from acute hospital 'interface geriatrics'. Age Ageing 20II; 40:436-43. http://dx.doi. org/10.1093/ageing/afr060

4 Conroy SP. Understanding frailty. Presentation at British Geriatrics Society Meeting 2009; Oct 7-9; Harrogate, Yorkshire.

5 Woodard J, Gladman J, Conroy S. Frail older people at the interface. JNHA 2009; I 3 (suppl I):S308.

6 Ellis G, Whitehead MA, O'Neill D et al. Comprehensive geriatric assessment for older adults admitted to hospital. Cochrane Database Syst Rev 201 I; 7:CD0062II.

7 Morley JE, Haren MT, Rolland Y et al. Frailty. Med Clin North Am 2006; 90:837-47. http://dx.doi.org/10.1016/j.mcna.2006.05.019

8 Nowak A, Hubbard RE. Falls and frailty: lessons from complex systems. J R Soc Med 2009; 102:98-102. http://dx.doi.org//0.1258/ jrsm.2009.080274

9 van den Bergh JP, van Geel TA, Geusens PP. Osteoporosis, frailty and fracture: implications for case finding and therapy. Nat Rev Rheumatol 2012; 8:163-72. http://dx.doi.org/10.1038/nrrheum.201I.217

10 Boyle PA, Buchman AS, Wilson RS et al. Physical frailty is associated with incident mild cognitive impairment in community-based older persons. JAm Geriatr Soc 20 I 0; 58:248-55. http://dx.doi.org/ I0. I I II/ j. I532-54I5.2009.0267I.x

\section{CONCLUSION}

Our study indicates that the prevalence of frailty is high in acute admissions of older patients. It is therefore important to have access to a frailty screening tool in daily acute care practice in hospitals. The elderly care medical team, as well as any other clinical team managing these elderly patients, must be able to undertake a comprehensive CGA and be able to apply the results effectively.

\section{Acknowledgements}

We would like to thank Drs A Win, $\mathrm{H}$ Chamberlain and A Noorin for their contributions to this paper.

II Buchman AS, Boyle PA, Wilson RS et al. Frailty is associated with incident Alzheimer's disease and cognitive decline in the elderly. Psychosom Med 2007; 69:483-9. http://dx.doi.org//0.1097/ psy.0b0I3e3I8068deld

12 Bowman C,Whistler J, Ellerby M. A national census of care home residents. Age Ageing 2004; 33:56I-6. http://dx.doi.org/I0.1093/ ageing/afh 177

I3 Lang PO, Michel JP, Kekry D. Frailty syndrome: a transitional state in a dynamic process. Gerontology 2009: 55:539-49. http://dx.doi. org/l0.1I59/000211949

I4 Fried LP,Tangen CM,Watson J et al. Frailty in older adults: evidence for a phenotype. J Gerontol A Biol Sci 200I; 56:146-56.

15 Morley J. Implementing frailty into clinical practice: we cannot wait. JNHA 2012; 7:599-600.

16 Sternberg SA, Wershof Schwartz A, Karunananthan S et al. The identification of frailty: a systematic literature review. J Am Geriatr Soc 20II; 59:2129-38. http://dx.doi.org//0.IIII/j.I532-54I5 20II.03597.x

17 Hulley SB, Cummings SR, Browner WS et al. Designing clinical research. 3rd ed. Philadelphia: Lippincott Williams and Wilkins; 2007. pp. 38-45.

18 Kalra P. Essential revision notes for MRCP. Ist ed. Knutsford: PasTest; 2003. pp. 648-53. 